\section{The benefits of nurse led secondary prevention clinics for coronary heart disease continued after 4 years} Murchie P, Campbell NC, Ritchie LD, et al. Secondary prevention clinics for coronary heart disease: four year follow up of a
randomised controlled trial in primary care. BMJ 2003;326:84-7.

\section{QUESTION: In patients with pre-existing coronary heart disease (CHD), do the benefits of nurse led secondary prevention clinics continue beyond 1 year?}

\section{Design}

Randomised \{allocation concealed * $^{*}$, unblinded*, controlled trial with mean follow up of 4.7 years.

\section{Setting}

19 randomly selected general practices in Scotland, UK.

\section{Patients}

1343 patients (mean age 66 y, 58\% men) who had CHD. Exclusion criteria were terminal illness, dementia, and inability to leave home. $82 \%$ of patients were followed up.

\section{Intervention}

673 patients were allocated to receive invitations to attend secondary prevention clinics at their general practice where nurses reviewed symptoms and treatments, promoted aspirin use, reviewed blood pressure and lipid management, assessed lifestyle factors, and negotiated any necessary behavioural changes. 670 patients were allocated to usual care. The intervention ended after 1 year, individual results were sent to the general practices, and patients in both groups were allowed to attend secondary prevention clinics if their general practitioners continued to offer them.

\section{Main outcome measures}

Use of secondary prevention (only blood pressure management and lipid management had $>80 \%$ follow up), total mortality, and coronary event rates (coronary death or non-fatal myocardial infarction).

\section{Main results}

Analysis was by intention to treat. Patients in the intervention group maintained the same level of secondary prevention use at 4 years, except for exercise. After the initial trial, increased use of secondary prevention in the control group resulted in no differences between the treatment and control groups at 4 years. Results were adjusted for age, general practice, sex, and baseline secondary prevention; the reduced total mortality and coronary event rates seen in the intervention group during the first year were sustained (table).

\section{Conclusion}

Nurse led secondary prevention clinics maintained secondary prevention use after 4 years, and the decreased mortality and coronary events seen in the first year remained at 4 years.

*Campbell NC, Thain J, Deans HG, et al. BMJ 1998; 316:1434-7.
Source of funding: Chief Scientist Office at the Scottish Executive.

For correspondence: Mr P Murchie,

Department of General Practice and Primary Care, University of

Aberdeen, Aberdeen,

UK.

p.murchie@abdn.ac.uk

A modified version of this abstract appears in Evidence-Based Medicine.

Nurse led secondary prevention clinics $v$ control in coronary heart diseaset

\begin{tabular}{lllll}
$\begin{array}{l}\text { Outcomes at } \\
\text { mean } 4.7 \text { years }\end{array}$ & $\begin{array}{l}\text { Nurse led } \\
\text { clinics }\end{array}$ & $\begin{array}{l}\text { Adjusted RRR } \\
\text { Control } \\
(95 \% \text { Cl) } \neq\end{array}$ & NNT (Cl) \\
\hline Total mortality & $15 \%$ & $19 \%$ & $25 \%(2$ to 42$)$ & $22(13$ to 265$)$ \\
\hline Coronary events§ & $14 \%$ & $18 \%$ & $24 \%(0$ to 42$)$ & Borderline significance \\
\hline
\end{tabular}

†Abbreviations defined in glossary; RRR, NNT, and $\mathrm{Cl}$ calculated from data in article.

$\ddagger$ Adjusted for age, general practice, sex, and baseline secondary prevention.

$\S$ Coronary death or non-fatal myocardial infarction.

\section{COMMENTARY}

Murchie et al appear to confirm the long term effectiveness of nurse run clinics for increasing secondary prevention in primary care settings. The use of the clinics by control patients after completion of the first trial meant that the initial difference between the treatment and control groups at 1 year disappeared. However, adjusted analyses suggest that patients attending the nurse run clinics had significantly better survival and fewer coronary events after approximately 5 years, with the suggestion that longer participation in the clinics yielded the best outcomes.

The effectiveness of nurse run clinics in reducing short term cardiovascular risk has been previously established. ${ }^{1-2}$ The maintenance of these improvements over the long term encourages further development of such programmes. However, the absence of discussion around a theoretical model for the nursing intervention might hinder the study's replication in other settings. The transtheoretical model is effective for many health behaviours and may add benefits here, as may the use of process evaluation. ${ }^{3-4}$

Secondary prevention with respect to appropriate medication use (aspirin, antihypertensives, and lipid lowering agents) has clear benefits, and nurses can improve patient compliance with such regimens by helping patients tailor regimens to their unique circumstances. The findings of Murchie et al suggest that, firstly, more research is necessary to determine ways in which nursing might contribute to equally impressive improvements in diet and exercise behaviour as were found for use of pharmacological treatments. Secondly, by studying effective practice models to guide nursing, results such as these may be more widely applied.

Marilyn Frenn, RN, PhD Associate Professor Marquette University College of Nursing Milwaukee

Wisconsin, USA

1 Benkert R, Buchholz S, Poole M. Hypertension outcomes in an urban nurse-managed center. J Am Acad Nurse Pract 2001;13:84-9.

Lindsay P, Sherrard H, Adam M, et al. The impact of a nurse-managed clinic for PTCA patient follow-up. Can J Cardiovasc Nurs 2000;11:13-20.

ue NH, Cunningham SL Stages of exercise behavior change at two time periods following coronary artery bypass graft surgery. Prog Cardiovasc Nurs 1998;13:23-33.

Taylor CA, Resick L, D'Antonio JA, et al. The advanced practice nurse role in implementing and evaluating two nurse-managed wellness clinics: lessons learned about structure, process, and outcomes. Adv Pract Nurs Q 1997;3:36-45. 